\title{
AOR
}

Selected Papers of \#AoIR2020:

The 22nd Annual Conference of the

Association of Internet Researchers

Virtual Event / 13-16 Oct 2021

\section{A TOPOGRAPHY OF VIRTUAL INFLUENCERS}

\author{
Rachel Berryman \\ Curtin University, Australia \\ Crystal Abidin \\ Curtin University, Australia \\ Tama Leaver \\ Curtin University, Australia
}

\section{Introduction}

Informed by my first six months of doctoral research, this paper offers a topography of virtual influencers that at once acknowledges their continuation of and breaking with the precedents of a lineage of "virtual beings" who have achieved celebrity status. Responding to the ahistoricism of much recent commentary, it draws on archival press and web research to situate virtual influencers at the intersection of technological advancements, discourses, and anxieties similarly characterising Hollywood's "synthespians" at the turn of the twenty-first century; the legacy of "virtual idols" in East Asia (also known as "Vocaloids" in Japan); and the latter's recent democratisation by a new generation of "vTubers" across video-sharing sites. Recognising this cross-medium migration of virtual celebrity-from anime, video games and blockbuster cinema to the participatory web-this paper adopts a platform-specific lens to highlight the affordances, cultures and vernaculars of specific social media as essential to virtual influencers' aspiration to, and attainment and maintenance of, attention and fame.

\section{What are Virtual Influencers?}

Virtual influencers are characters native to social media, with no singular referent in the offline world. Ranging in appearance from eerily humanoid to entirely fantastical, and utilising computer-generated imagery and animation of varying sophistication, quality and photorealism, virtual influencers are typically designed to accumulate audiences and promote products, brands and/or messages. Spanning several social media platforms, this paper focuses on virtual influencers' established presence on Instagram, Twitter, YouTube, TikTok and Sina Weibo, where they pique curiosity through their strategic blurring of fiction and reality, evoking roboticist Masahiro Mori's (1970/2012) theorisation of the "uncanny valley" not only with their anthropomorphised designs, but also by infusing their content with imagery of real locations and people, and popular social media aesthetics and platform vernaculars in ways that seem to affirm their "authenticity" (Leaver et al., 2020). 


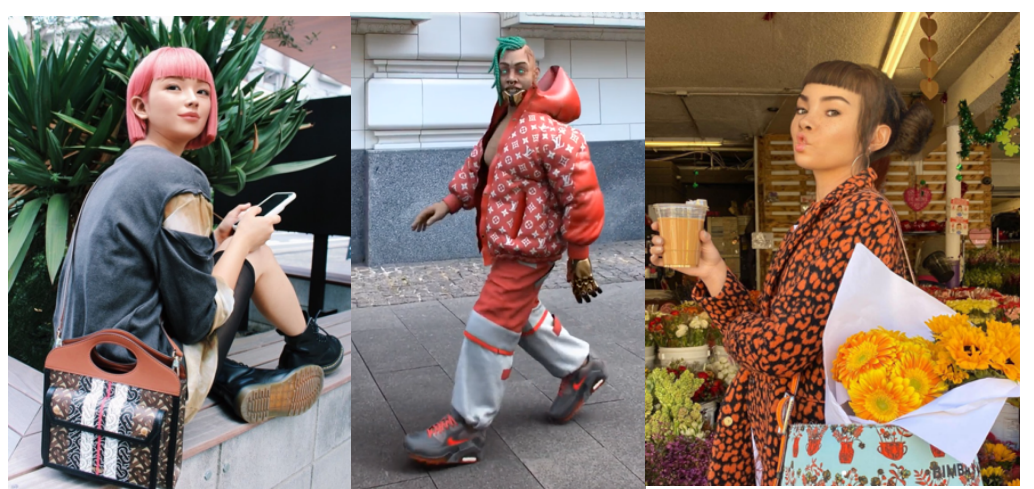

Figure 1: @imma.gram (2020, Japan) with a beloved Burberry handbag, @FNMeka (2020, US) flaunting a new streetwear ensemble, and @lilmiquela (2020, US) snapped on an outing to a local flower shop.

Since the mid-2010s, virtual influencers have attracted substantial press coverage and multiplying follower counts, with the most popular characters addressing hundreds of thousands of followers with their regular content uploads and "life" updates (Figure 1). As with their corporeal counterparts (see Abidin, 2018), this visibility has unlocked a litany of commercial opportunities, inspiring a budding industry interested in mobilizing their platforms for a parade of sponsored content and partnerships. Major brands have taken to designing their own virtual influencers as a marketing approach (Figure 2), and not-for-profit organisations have leveraged their effectiveness at attracting and engaging audiences to more widely promote important causes (Figure 3).

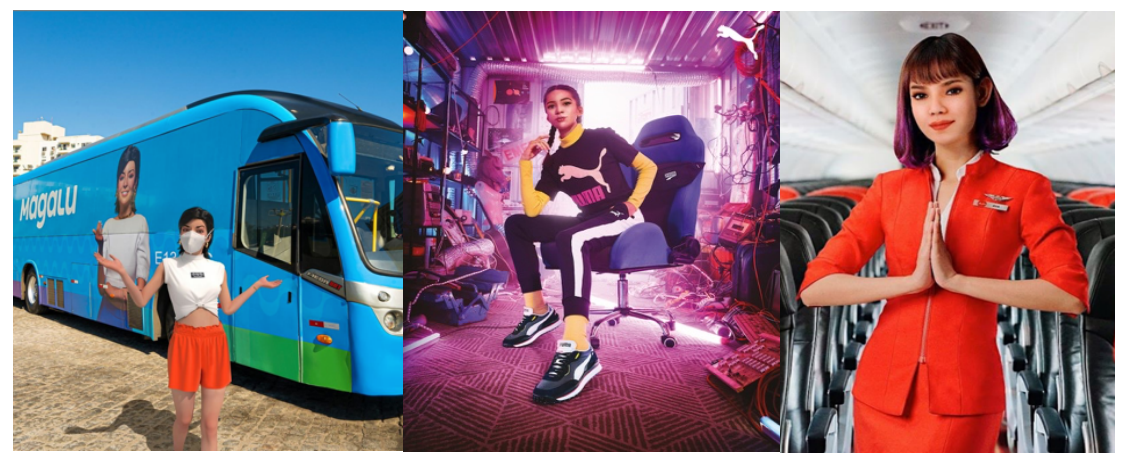

Figure 2: Big-box retailer @magazineluiza's virtual ambassador Lu (2015_, Brazil), Puma’s @mayaaa.gram (2020-2020, South East Asia), and AirAsia’s @missava (2019-2020, Malaysia).

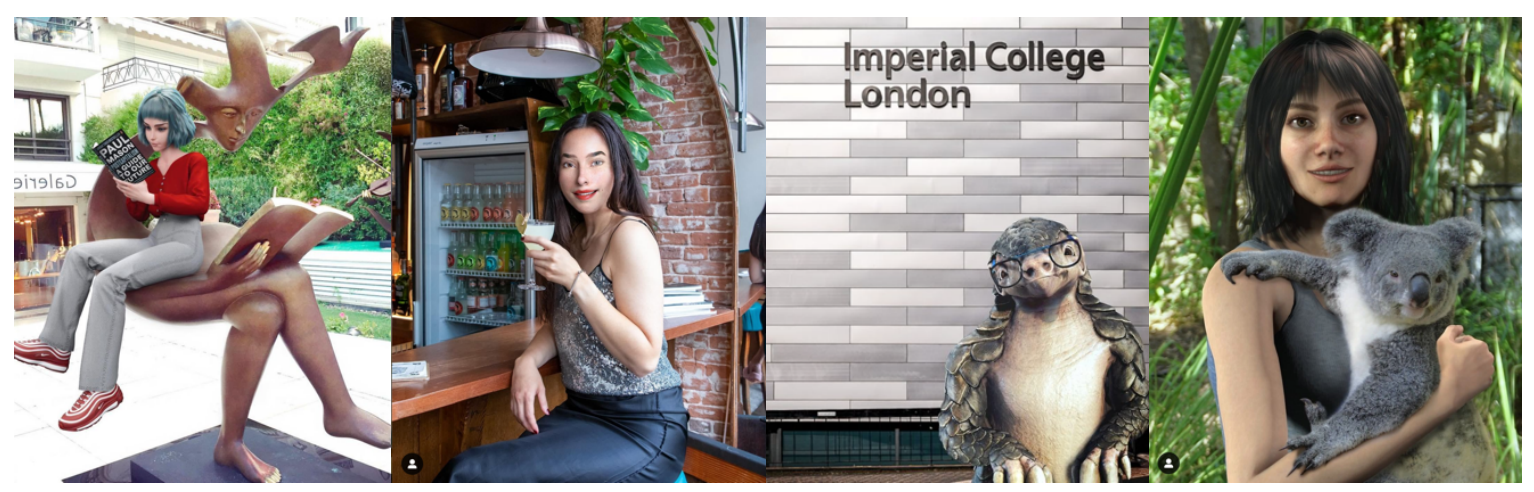

Figure 3: Economics education advocate @ruby.economics (2018-2020, Germany), local guide @esther.olofsson (2020_, Netherlands), and conservation ambassadors @eric_the_pagolin (2020_, UK) and @wildlife.watcherau (2020_, Australia). 


\section{A Brief History of Virtual Celebrity}

At the turn of the twenty-first century, the advent of motion-capture and ongoing refinements to computer-generated artistry were enabling increasingly photorealistic visual spectacles, doubles and enhancements. This, in turn, stoked speculation about the future of virtual actors, known as "synthespians" ("synthetic thespians"), in Hollywood films (Leaver, 2012). With press abuzz with news of A-list celebrities undergoing scans to create their own datafied doubles and scandalized accounts of deceased actors' digital reanimation (Figure 4), talk quickly turned to the possibility synthespians would someday enter the Hollywood star system (Creed, 2000). Elsewhere, however, these fantasies were already a reality.

\begin{tabular}{|c|c|c|}
\hline RollingStone & Los Angeles Cimes & 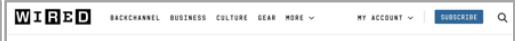 \\
\hline 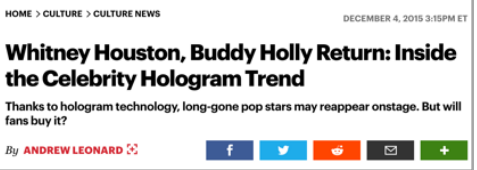 & 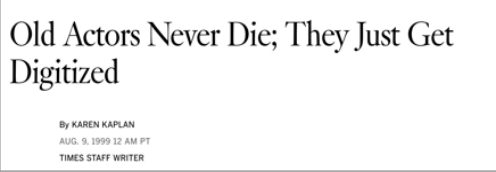 & 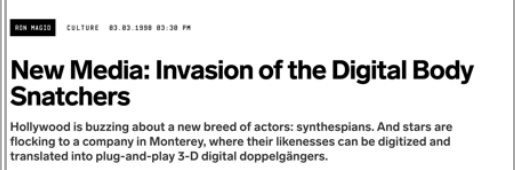 \\
\hline 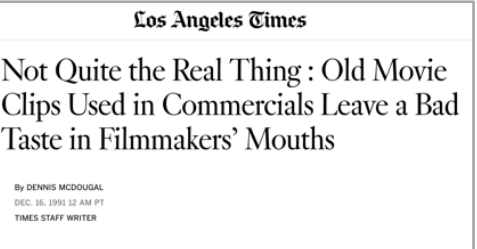 & 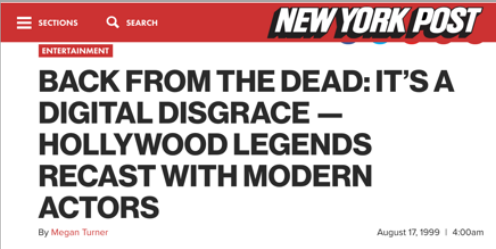 & $\begin{array}{l}\text { Film } \\
\text { Things to do in Hollywood when you're } \\
\text { dead } \\
\text { Steve McQueen is selling cars. Fred Astaire is advertising } \\
\text { condoms, and Marlene Dietrich is about to star in aromantic } \\
\text { comedy opposite George Clooney. Now that we have the } \\
\text { technology tobring screen stars back from the grave, Brian } \\
\text { Logan asks: do we really want it? }\end{array}$ \\
\hline
\end{tabular}

Figure 4: Media respond to reanimated Hollywood celebrities advertising Diet Coke (1991); unveiled as photorealistic digital doubles (1998-1999); and later, delivering posthumous, holographic performances (2015).

Emerging from the idol (aidoru) culture that has saturated Japan's entertainment industries since the 1980s (see Karlin \& Galbraith, 2012), the first digitally-produced virtual idol, Kyoko Date, was unveiled by talent agency HoriPro in 1996. A combination of 3D-modelling, motion-capture and voice artistry, the 16-year-old virtual idol released pop singles, starred in music videos, and featured on radio and television shows. Kyoko's debut was a moderate success, albeit fleeting; unable to find a foothold in popular consciousness, she was eventually retired, although briefly revived in 2001 and 2007 (Black, 2012). A subsequent generation of virtual idols, including Japan's Yuki Terai (1998-2002), South Korea's Adam (1997-1998), and Germany's E-Cyas (1999-2000), met similar fates.

The virtual idol concept was revitalized, however, by the release of Yamaha's Vocaloid synthesizer software in the early 2000s, and the avid interest in the animated character for one of its vocal tracks, Hatsune Miku, that quickly followed. Since her debut in 2007, Hatsune has inspired a dedicated and collaborative fanbase who write, produce, choreograph, consume, share and remix songs using her voice and design. Fuelled by her fans' creativity and support, Hatsune has become a global icon, regularly headlining sell-out concerts, and appearing in advertisements, television shows, video games, soundtracks, books and magazines (Black, 2012; Sone, 2017).

More recently, increasingly affordable animation software and motion-capture hardware have presented new opportunities for those interested in courting virtual idoldom. Animating users' (typically anime-inspired) appearance and movements, facilitating mobile recording and instantaneous broadcasting, these new tools have 
given rise to a rapidly expanding cohort of "vTubers" (virtual YouTubers), who produce a variety of popular vlogs, collaboration, reaction, challenge and gameplay videos across platforms such as YouTube, Bilibili, Niconico and Twitch.

\section{The Advantages of Virtuality}

Contrasting Hatsune's prolific career with prototypical virtual idols, Japanese studies scholar Daniel Black (2012) posits that, to be successful, a virtual idol's "digital translation of a [performer's] body" must embrace the "new attributes particular to her digital format" (p. 219). If, for Hatsune, this involved the networked creativity and participatory fandom of the mid-2000s web (Sone, 2017), for virtual influencers, it is their embrace of the affordances and vernaculars of specific social media, and further, their adoption of strategies of social media microcelebrity (see Marwick, 2018).

In these efforts, however, compared to corporeal influencers, the immateriality of virtual influencers affords greater:

- Flexibility of characterisation, enabling differentiation from other influencers, and/or crafted relatability for specific audiences (Figure 5);

- Plasticity of self-branding, enabling updates that reflect trending aesthetics, styles and/or audience feedback (Figure 6); and

- Access to locations, products and collaborators otherwise restricted by availability, cost or practicability (Figure 7).

Such qualities present an advantage for the "visibility labour" (Abidin, 2016) involved in microcelebrity practice, presenting unique ways of maintaining a "noticeable and positively prominent" online presence (Abidin, 2016, p. 90) requisite for successfully navigating social media's hyper-competitive economies of attention and affection (see Abidin, 2018).
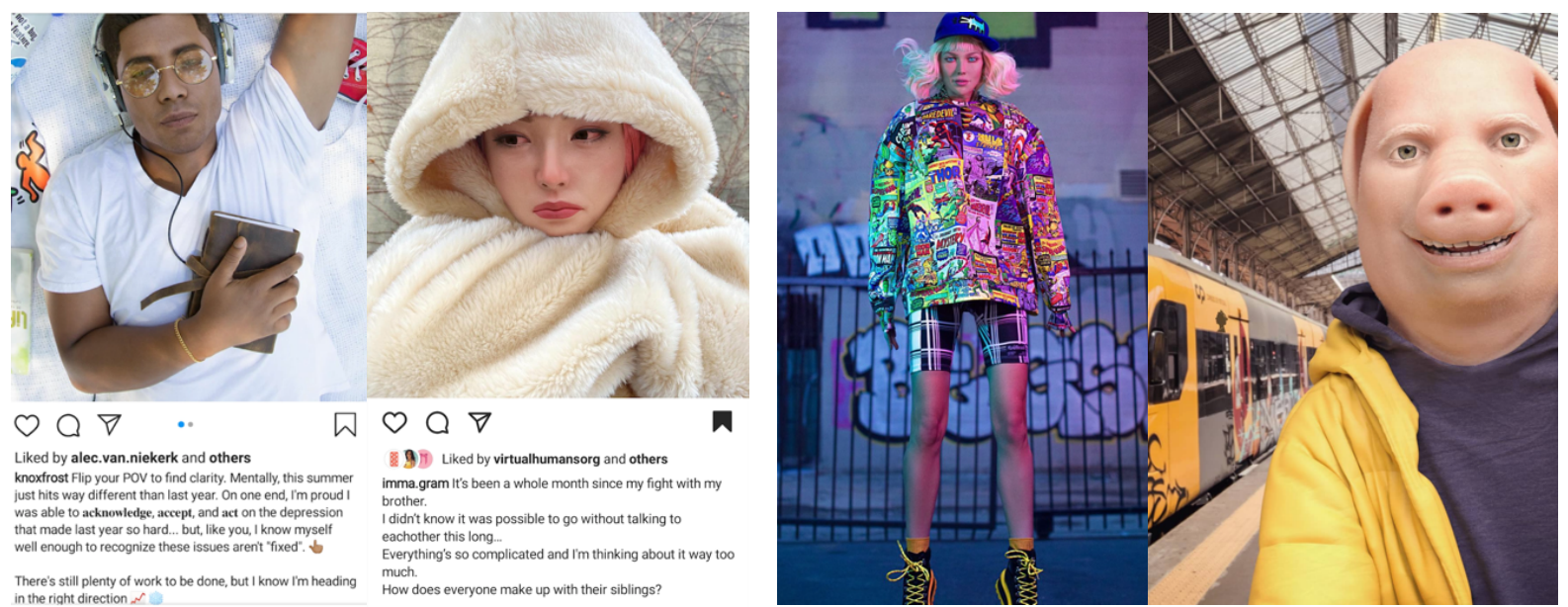

Figure 5: @knoxfrost (2020, US) and @imma.gram (2021, Japan) share their struggles with mental wellbeing, encouraging audience identification; alien @itsbinxie (2020, US) and pig-man @john_pork (2020, UK) stand out as extraordinary species. 

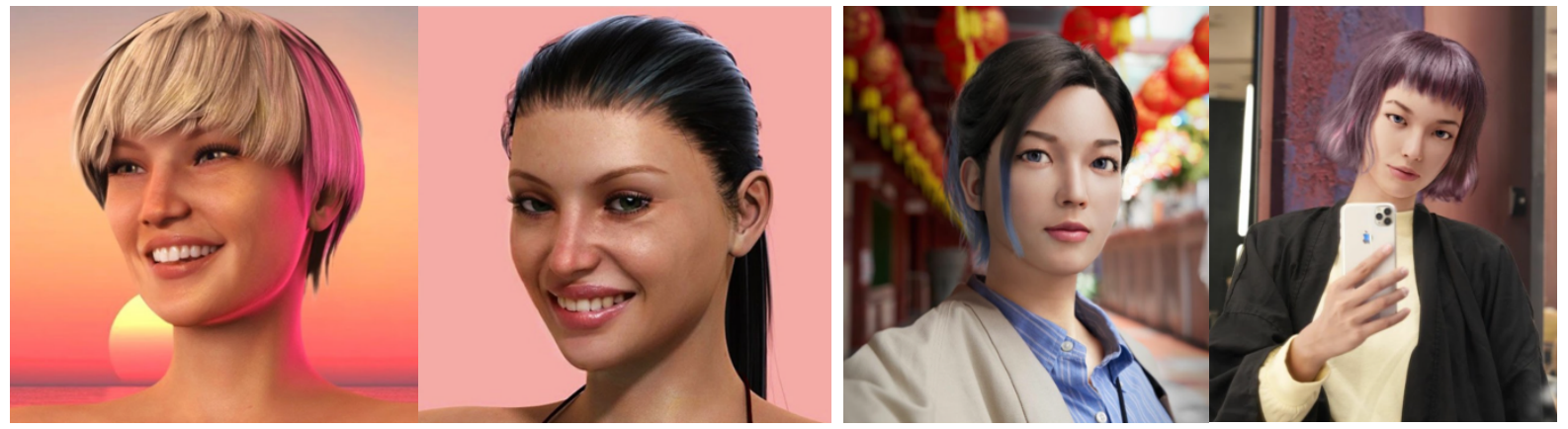

Figure 6: @amanda_bims (2020, 2021, Unknown) and @here_is_rae (2021, Singapore) unveil their updated "looks" (left: old; right: new).

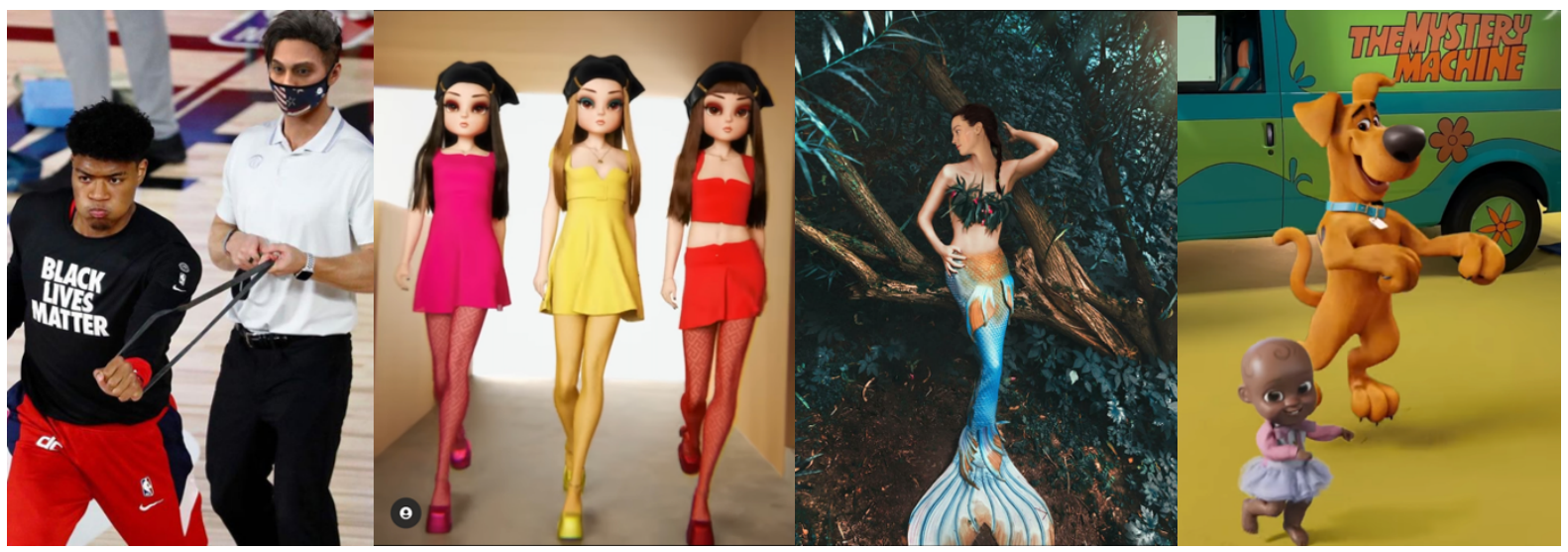

Figure 7: @liam_nikuro (2020, Japan) attends a closed NBA training during COVID-19 lockdown; @noonoouri (2021, Italy) spawns doubles for the \#VersaceRunwayChallenge; @leyalovenature (2021, Switzerland) models as a mermaid; and @realqaiqai (2020, US) dances with Scooby Doo.

Table 1: Definitions of vocabulary related to virtual celebrity.

\begin{tabular}{|c|c|c|c|}
\hline Term & Alternative Terms & Definition & Examples \\
\hline Synthespian & virtual actor, vactor, artifactor & $\begin{array}{l}\text { Abbreviation of "synthetic thespian," originating in the visual effects industry in the } \\
\text { late } 1980 \text { s. An actor made either in part or entirely using computer-generated } \\
\text { graphics, typically in combination with motion or performance capture technology. }\end{array}$ & $\begin{array}{l}\text { - Jar Jar Binks in Star Wars: Episode I - The Phantom } \\
\text { Menace (1999) } \\
\text { - Aki Ross in Final Fantasy: The Spirits Within (2001) } \\
\text { - Gollum of the The Lord of the Rings trilogy (2001- } \\
\text { 2003) }\end{array}$ \\
\hline Virtual Beings & & $\begin{array}{l}\text { A collective term for humanoid or anthropomorphised creations made using digital } \\
\text { technologies. May be dis/embodied, and expressed through text, voice, graphics, } \\
\text { or a combination thereof. Includes static and animated creations, as well as those } \\
\text { powered by artificial intelligence or machine-learning. }\end{array}$ & $\begin{array}{l}\text { - Siri (2011—) } \\
\text { - Lara Croft of the Tomb Raider video game franchise } \\
\text { (1996-) } \\
\text { - Ananova (2000-2004) }\end{array}$ \\
\hline Virtual Idol & $\begin{array}{l}\text { バーチャルアイドル } \\
\text { (bācharu aidoru), } \\
\text { 仮想アイドル (kasō aidoru) }\end{array}$ & $\begin{array}{l}\text { Ficticious musical performers, originally appearing in anime and video games, } \\
\text { though eventually describing characters created with digital technologies. Virtual } \\
\text { idols transcend a single media property, and are known to pursue musical careers, } \\
\text { featuring vocals by voice artists or synthesizer software (see Vocaloid). }\end{array}$ & $\begin{array}{l}\text { - Kyoko Date }(1996-1997) \\
\text { - Diki (1999) } \\
\text { - Yuki Terai }(1998-2002)\end{array}$ \\
\hline Virtual Influencers & $\begin{array}{l}\text { CGI Influencers, Al Influencers, } \\
\text { Biodigital Influencers, Virtual } \\
\text { Endorsers, Algorithmic Online } \\
\text { Celebrities }\end{array}$ & $\begin{array}{l}\text { Characters that exist on social media, with no singular referent in the offline world, } \\
\text { designed and maintained for the purpose of promoting products, brands and/or } \\
\text { messages. Ranging in appearance from eerily humanoid to entirely fantastical, and } \\
\text { made using animation and computer-generated effects of varying sophistication, } \\
\text { quality and degrees of photorealism. }\end{array}$ & $\begin{array}{l}\text { - @lilmiquela (2016-) } \\
\text { - @noonoouri (2018-) } \\
\text { - @FNMeka (2019-) }\end{array}$ \\
\hline Vocaloid & ボーカロイド (bōkaroido) & $\begin{array}{l}\text { Popular animated characters created by Crypton Future Media to represent the } \\
\text { voice banks of Yamaha's Vocaloid synthesizer software. Fans create, share and } \\
\text { circulate user-generated content featuring the characters' voice and image, co- } \\
\text { authoring their persona and collaborating on their celebrification. Known for "live" } \\
\text { performances using holographic displays. }\end{array}$ & $\begin{array}{l}\text { - Hatsune Miku }(2007-) \\
\text { - Kagamine Len \& Rin }(2007-) \\
\text { - Megurine Luka (2009-) }\end{array}$ \\
\hline $\begin{array}{l}\text { vTuber, } \\
\text { Virtual YouTuber }\end{array}$ & $\begin{array}{l}\text { ブイチューバー (buichūbā), } \\
\text { バーチャルユーチューバー } \\
\text { (bācharu yūchūbā) }\end{array}$ & $\begin{array}{l}\text { Abbreviation of "Virtual YouTuber." A digital content creator whose actions and } \\
\text { voice are expressed through an animated character. Most commonly Japanese } \\
\text { speaking, with 2D or 3D anime-inspired designs, rigged for face and motion } \\
\text { capture technologies. Popular across several user-generated video and live- } \\
\text { streaming platforms; not exclusive to YouTube. }\end{array}$ & $\begin{array}{l}\text { - Ami Yamato (2011-) } \\
\text { - Kizuna Al (2016-) } \\
\text { - Rin Asobi (2018-) }\end{array}$ \\
\hline
\end{tabular}




\section{Works Cited}

Abidin, C. (2016). Visibility labour: Engaging with Influencers' fashion brands and \#OOTD advertorial campaigns on Instagram. Media International Australia, 161(1), 86-100.

Abidin, C. (2018). Internet Celebrity: Understanding Fame Online. Emerald.

Black, D. (2012). The Virtual Idol: Producing and Consuming Digital Femininity. In P. W. Galbraith \& J. G. Karlin (Eds.), Idols and Celebrity in Japanese Media Culture (pp. 209-228). Palgrave Macmillan.

Creed, B. (2000). The Cyberstar: Digital Pleasures and the End of the Unconscious. Screen, 41(1), 79-86.

Karlin, J. G., \& Galbraith, P. W. (Eds.). (2012). Idols and Celebrity in Japanese Media Culture. Palgrave Macmillan.

Leaver, T. (2012). Artificial Culture: Identity, Technology, and Bodies. Routledge.

Leaver, T., Highfield, T., \& Abidin, C. (2020). Instagram: Visual Social Media Cultures. Polity.

Marwick, A. E. (2018). The Algorithmic Celebrity: The Future of Internet Fame and Microcelebrity Studies. In Microcelebrity Around the Globe (pp. 161-169). Emerald Publishing Limited.

Mori, M. (2012, June). The Uncanny Valley (K. F. MacDorman \& N. Kageki, Trans.). IEEE Robotics Automation Magazine, 19(2), 98-100. (Original work published 1970)

Sone, Y. (2017). Japanese Robot Culture. Palgrave Macmillan US. 